\title{
Cartografías espaciales y estéticas corporales en Guadalupe Santa Cruz, Lina Meruane y Diamela Eltit ${ }^{\star}$
}

Space cartographies and body aesthetics in Guadalupe Santa Cruz, Lina Meruane and Diamela Eltit

\section{MónICA BaRRIentos}

Universidad Autónoma de Chile

DOI: https://doi.org/10.32719/13900102.2018.44.9

Fecha de recepción: 11 enero 2018

Fecha de aceptación: 23 marzo 2018

Licencia Creative Commons

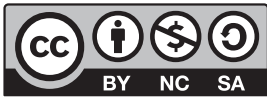




\section{RESUMEN}

Este trabajo analiza el espacio como un elemento fundamental para el estudio de tres escritoras chilenas contemporáneas -Guadalupe Santa Cruz, Lina Meruane y Diamela Eltit-. En sus novelas, el espacio de la ciudad se presenta como forma de cuestionamiento al canon, ya que la representación literaria de la ciudad real se produce desde una nueva retórica urbana: una que elabora otras formas de pensar la relación entre significante y significado en función del referente real -ya sea urbano, de paisaje, mapas, cartografías, formas de habitar-, y la situación comunicativa imaginaria propia de las novelas.

Palabras clave: Chile, novela, Guadalupe Santa Cruz, Lina Meruane, Diamela Eltit, espacios, cuerpos, cartografías.

\section{ABSTRACT}

This paper analyzes space as a key element for the study of three Chilean contemporary writers: Guadalupe Santa Cruz, Lina Meruane and Diamela Eltit. In their novels, urban space appears a way for questioning the established canon, since the literary representation of the real city arises from a new urban rhetoric: one that elaborates other ways of conceiving the relationship between signifier and signification according to the real referent -whether urban, landscape, maps, cartographies, inhabitation-, and the imaginary communicative situation inherent to novels.

KEYwords: Chile, novel, Guadalupe Santa Cruz, Lina Meruane, Diamela Eltit, spaces, bodies, cartographies.

El derecho a la ciudad es un significante vacio. Todo depende de quién lo llene y con qué significado [...] Los financieros y promotores pueden reclamarlo y tienen todo el derecho a hacerlo; pero también pueden bacerlo los sin techo y sin papeles [...]

La definición del derecho es en sí mismo objeto de una lucha que debe acompañar a la lucha por aterializarlo. La ciudad tradicional ha muerto. David Harvey, Ciudades rebeldes

EL ESPACIO EN la literatura siempre ha sido un tema importante y transversal en los análisis críticos. Si observamos los textos clásicos de teoría literaria, veremos que existe una primacía del narrador y su perspectiva, que concibe el espacio como un telón de fondo de los personajes y de los hechos narrados, a pesar que el espacio ha sido un elemento importante en la narrativa latinoamericana desde sus comienzos. En las literaturas nacionales de inicios del silgo XIX hasta las más contemporáneas que abordan 
la irrupción de las periferias, las migraciones, la globalización y los multiculturalismos, el espacio literario ha tenido una importancia primordial que, muchas veces, no ha sido considerado en el mismo nivel que otros componentes dentro del análisis literario. Para Alicia Llarena, el espacio en la literatura hispanoamericana es paradójico porque a pesar de "su incidencia directa en los momentos centrales de su proceso histórico, de su peso específico en la representación de América y sus estrechas relaciones con la definición de identidad [...] ha sido un elemento singular y contradictorio, celebrado y rechazado a un tiempo" (Llarena 2007, 10).

El espacio entonces ha sido un elemento estructural de la identidad cultural y de la imagen de América Latina desde los textos de los conquistadores, pasando por los "telúricos" regionales a los textos que imaginan las urbes del siglo XX. En todos ellos, sin embargo, la ciudad, o la idea de ella, fue un horizonte siempre buscado, dibujado y cartografiado. Desde los inicios de la modernidad, el espacio urbano y su representación en la literatura se relacionan con la ciudad real y su posibilidad de mimesis; es decir, con la capacidad de reflejar los hechos y estructuras que ella contiene en la literatura. Lucía Guerra afirma que la ciudad se pensó primero como un plano conformado por un conjunto de líneas, convergencias y divergencias, pero que omiten todo relieve y esconden las connotaciones de profundidad, densidad y volumen que las ciudades contienen. De este modo, la ciudad se convierte en un "locus, por excelencia, de la producción y circulación de un orden social y político implementado por una estructura de poder" (Guerra 2014, 12), que organiza desde lo material hasta los cuerpos de sus habitantes.

La fragilidad y la precariedad de la existencia, la incertidumbre por la posible pérdida de bienes materiales, la falta de seguridad y el miedo al "otro", son temores fundamentales que aparecen en las calles de las ciudades y que brotan en formas de violencia, segregación espacial y nuevas tecnologías que permiten mantener la seguridad, ya sea económica o geográfica. La circulación y el modo de habitar de los cuerpos implican una relación subjetiva con el espacio urbano, y un sistema codificado a partir de símbolos culturales que no aparecen mapeados, pero que muestran la circulación de un orden social y sus dinámicas de poder. En este artículo queremos decodificar y leer la ciudad a partir de tres narradoras chilenas: Guadalupe Santa Cruz, Lina Meruane y Diamela Eltit. En la obra de estas escritoras, los espacios citadinos se presentan simbólicamente como forma 
de cuestionamiento del canon, debido a que la intención de representar en las obras la ciudad real se produce por medio de una nueva retórica urbana: una que elabora otras formas de representación con respecto al referente real -ya sea urbano, de paisaje, mapas, cartografías, formas de habitar-, y la situación comunicativa imaginaria propia de las novelas.

La representación imaginaria del espacio se centra principalmente en la figura de la ciudad como reserva de los diferentes tópicos de Occidente. Es lo que Cristián Cisternas llama "la retórica literaria de la representación urbana": "la representación de la ciudad no solo enriquece el nivel hermenéutico de las obras literarias sino que, además, provee explicaciones metafóricas para disciplinas como la urbanística y la biología" (Cisternas 2009, 17). Es por ello que el modelo de análisis del cronotopo, como un tópico recuperado, permite transformar motivos literarios junto con la continuidad de las posturas ideológicas de Occidente; por ejemplo, el tópico del carpe diem que es recuperado como una crítica a la sociedad de consumo, o la sociedad como espectáculo en el tópico del "teatro mundo". Este acercamiento permite identificar una tradición interpretativa sobre la representación literaria de la ciudad con sus variaciones históricas y la imagen del habitar urbano en relación con el mundo representado, configurándose como los puntos coyunturales en el análisis de Cisternas. ${ }^{1}$ Sobre esta perspectiva nos preguntamos: ¿cómo se configuran los espacios en las narrativas actuales? ¿De qué forma podemos analizar la tensión y distensión entre los cuerpos, los espacios y las subjetividades en las novelas seleccionadas? La ciudad es el escenario principal de todas estas obras, su condición es amplia y compleja, ya que los personajes conviven con otros con quienes apenas se relacionan. Sin embargo, la condición de la ciudad también exige la construcción de imágenes que puedan atrapar esa realidad, que muchas veces excede al individuo y nutre el campo de lo imaginario. Es lo que Michel De Certeau denomina la "otra espacialidad": una que se nutre de la experiencia antropológica, poética y mítica del espacio. En esta identificación entre interioridad y ciudad, el sujeto urbano se erige frente a un espejo en el cual se mira, y comprueba que la ciudad ha dejado de ser solamente un abigarrado complejo semiológico a ser leído,

1. Para Cisternas, "el cronotopo actualiza en el espacio urbano contemporáneo una serie de tópicos relativos a una concepción del espacio-tiempo como construcción simbólica y metafórica de carácter ambiguo", por ejemplo, tópico del teatro del mundo con el concepto de sociedad del espectáculo (Cisternas, 23). 
para convertirse en una instancia narrativa donde se puede leer su propia historia. Las calles, las plazas, las casas y bares que cartografían la ciudad se convierten, al mismo tiempo, en espacios que se pueden leer desde la normalización del poder, pero también desde la resistencia de algunos habitantes. Los personajes de las novelas entablan un diálogo contaminado o perverso, pues mientras habitan esa otra instancia dialógica son, simultáneamente, habitados por ella. Más aún, este diálogo es también una posibilidad riesgosa porque en esta indefinible discursividad urbana, la exposición a lo "otro", lo extraño o ajeno y los poderes que la conforman, son la norma general.

Si afirmamos que existe más de una concepción acerca del espacio, y presuponemos que este es algo más que una superficie con propiedades físicas, ¿qué es entonces el espacio? Para Doreen Massey, el espacio puede ser conceptualizado en función de tres aspectos: el primero se refiere al espacio como producto de interrelaciones; es decir, de la interacción que se configura desde lo más global hasta lo más íntimo. El segundo aspecto entiende el espacio como una "esfera de posibilidad de la existencia de la multiplicidad" en la que coexisten diferentes trayectorias y múltiples voces: espacio y multiplicidad son constitutivos. Finalmente, el espacio siempre está en proceso de formación, abierto, en devenir. Es por ello que el espacio ya no es visto como una entidad estática, sino desde una perspectiva dinámica y fluida que depende de las relaciones instaladas dentro de este espacio-tiempo. Massey propone un concepto de lugar antiesencialista, que reconoce diferencias y subraya las bases de solidaridades potenciales que puedan dar fe de los sujetos que se forman en ella: "En lugar de aceptar y trabajar con las identidades ya constituidas, esta política antiesencialista pone el acento en la constructividad de las identidades y los objetos" (Massey 2005, 106). El espacio es un proceso y es definido por el afuera donde se imbrican muchas identidades e historias, por lo que la identidad de un lugar no es fija porque las relaciones que se dan al interior de este son dinámicas. En esta misma línea de análisis, Henri Lefebvre plantea que el espacio no es un objeto separado de la ideología o de la política, sino que es político y estratégico con apariencia de neutralidad, pero formado a través de procesos históricos y naturales que son conjuntamente procesos políticos. Para ello, el autor presenta una trilogía espacial constituida por tres momentos interconectados (Lefebvre 2013, 33). El primero se refiere a las "prácticas espaciales", a las formas en que las personas generan, 
utilizan y perciben el espacio. El segundo apunta a las "representaciones del espacio" que están unidas a las relaciones de producción y orden de la vida cotidiana en un espacio concreto (a través de formas de conocimiento, saberes técnicos y racionales vinculados a un poder dominante, que producen la abstracción y descorporización del espacio). Finalmente, el “espacio representacional” es el espacio vivido por medio de sus símbolos y construcción de imágenes que se vinculan con la cultura y el arte; por lo tanto, se producen y modifican a través del tiempo y representan formas de conocimientos locales e informales que son dinámicas, simbólicas y saturadas de significados. Estos espacios están articulados en las vidas cotidianas y constituyen lo que Lefebvre llama "sitios de resistencia".

Junto al caos de representaciones que contiene el tópico de la ciudad, es necesario indicar que este espacio no se encuentra construido solo por estructuras y señales, sino que hay cuerpos que la recorren y la habitan. Por lo tanto, existe una versión oficial y una subjetiva de ella, por lo que el género es un factor importante para comprender el imaginario espacial urbano. La ciudad como cuerpo, entendido desde la anatomía, es un tópico clásico en la literatura occidental, donde cuerpo-ciudad "han encontrado relación en la arquitectura, en la planificación urbana, y en la práctica de la misma”, como afirma Sennett (1997, 17). En estas prácticas, la ciudad ha modelado su estructura para la conformación de un modelo patriarcal centrado en la reproducción biológica y laboral, manteniendo la dicotomía público/privado que obliga a la mujer a localizarse en el espacio privado de la reproducción biológica. Sin embargo, la mayor presencia de la mujer en el campo laboral y político ha promovido avances en las áreas sociales, pero la categoría genérica del espacio urbano todavía tiene poca representación. Algunos discursos feministas han elaborado estudios sobre la intersección del género sexual y la topografía urbana, ${ }^{2}$ afirmando que la vivencia de lo urbano es diferente para el hombre y la mujer, ya que para uno es posibilidad de desplazamiento, mientras que para la otra es amenaza, censura y/o vigilancia. Al respecto, Elizabeth Grosz sostiene:

The city is one of the crucial factors in the social production of (sexed) corporeality: the built environment provides the context and coordinates for contemporary forms of body. The city provides the order and organization

2. Entre ellas se encuentran Elizabeth Grosz, Doreen Massey, Gilliam Rose, Saskia Sassen, Alicia Lindón, Nancy Duncan, entre otras. 
that automatically links otherwise unrelated bodies: it is the condition and milieu in which corporeality is socially, sexually, and discursively produced. But if the city is a significant context and frame for the body, the relations between bodies and cities are more complex than may have been realized $(1995,104)$.

Las relaciones entre los cuerpos y la ciudad son tan heterogéneas que involucran una serie de flujos, sistemas, identidades y relaciones dispares. Es por ello que en este artículo veremos algunos imaginarios urbanos en el contexto de esta compleja relación entre género, ideología, espacio y sincronía histórica, como formas de representación de una ciudad latinoamericana que explora los bordes, los márgenes y cuestiona la forma de habitar estos espacios construidos desde un modelo preestablecido.

\section{LOS ESPACIOS DESPLAZADOS: CITA CAPITAL DE GUADALUPE SANTA CRUZ}

Las grandes ciudades y sus calles, desde la conformación de la modernidad, ya no son entendidas como el espacio de protección o identidad, sino que se han convertido en una causa de peligro. Por ello se potencia la capacidad de las estructuras espaciales de rechazar, excluir, esconder y resistir aquello que pueda generar algún grado de riesgo, controlando su estructura con la finalidad de garantizar la seguridad en todo momento. La adaptación de los sujetos a este orden social es fundamental porque no solo se realiza mediante la vigilancia y el control, sino también mediante la universalización de métodos disciplinarios como conjunto de técnicas y de instituciones que tienen la tarea de medir, controlar y corregir a quienes no se ajustan a estas normas.

Sin embargo, los cambios históricos y culturales han provocado que la ciudad y su forma de habitarla ahora es percibida como movible y reapropiada por combinaciones de fuerzas que escapan de las disciplinas y la mirada panóptica. La ciudad es entonces uno de los factores cruciales en la producción social de corporalidad (sexuada), ya que define la construcción de la imagen territorial, el paisaje y el punto de referencia de las nociones de intercambio económico, social y cultural en la generación de un orden y una organización que automáticamente se enlazan con los cuerpos. Por 
lo tanto, la ciudad es el locus más concreto de producción y circulación de poder, que funciona como una fuerza activa al constituirse con los cuerpos y siempre dejar huellas en la corporalidad de los sujetos.

Es por ello que la obra de Guadalupe Santa Cruz, prolífica escritora y artista visual que ha tenido como propuesta cartografiar la ciudad de Santiago, representa de mejor forma este desplazamiento de los cuerpos en un espacio urbano. En sus obras, los personajes recorren la ciudad y el país a pie, en buses, en mapas, siguiendo los signos de los recorridos o infiltrándose por lugares menos transitados. En su novela Cita capital (1992), Santa Cruz nos desplaza por toda la ciudad de Santiago, describiendo su topografía, sus recorridos de locomoción colectiva, los lugares emblemáticos y otros desconocidos para un habitante común. Con un mapa y como un mapa, la protagonista, Sandra, recorre la ciudad en forma compulsiva en busca de algo que la ayude a sincronizar las experiencias de un pasado violento donde sufrió la tortura y un presente que no logra conectar: “¿Dónde se encuentra la huella de mi daño?” (1992, 169). Esto es lo que persigue la protagonista en este exceso de búsqueda de una ciudad, que intenta convertirse en territorio, aunque la protagonista no logra asir y recorrer debido a su turbulencia y caos:

Le hemos puesto nombre a todo, en el viejo continente. Los barrios, las catedrales, los bosques, las enfermedades, las edades. Todo se encuentra bautizado, dijo Octavio.

$-¿$ Viniste buscando tierra virgen?

-Vine a conseguir mi propio nombre, lejos (15).

Por otro lado, Octavio, su pareja pasajera, un hombre que viene a reconocer Chile desde Europa porque la tumba de su madre se encuentra aquí, también se desplaza por Santiago ayudado de un mapa para intentar reunirse con el recuerdo de su madre, una patria y una identidad que no logra comprender: "¿Pero dónde encontrar este nombre, esta identidad, esta unión con el pasado? Octavio nos responde que están escondidos en algún lugar de la ciudad, puesto que existe una memoria encerrada en los objetos" (17). Ambos personajes, uno desconectado de su pasado y el otro que intenta conectarse excesivamente, inician juntos el recorrido de la ciudad siguiendo los puntos cardinales para buscar ese nexo: 
Su lengua, como serpiente, busca mi nombre. Me dejo tensar por la cuerda, sin voz. [...] mi cuerpo se da vuelta en torno a ese nudo... Todos los lugares y cuerpos en aquel intersticio que me ayuda a abrir. Me fuerza a ser una a través de él, para hacerlo debe reunirse con su dolor, su capital (17).

En Cita capital, Sandra, al igual que una flêneur, recorre la ciudad en forma errática, sin ninguna intención de territorializar su deambular: hace de la ciudad su cuerpo. De este modo, la ciudad es un cuerpo con anatomía y órganos que son analizados e intervenidos por Octavio, quien además es médico cirujano. La ciudad para Octavio es también el cuerpo de Sandra que no logra obtener del todo, debido a su desconocimiento, a su lejanía y a su imposibilidad de abrirse: "La ciudad, se decía, esta cabeza que sobresale en la dispersión, erigida como límite. Lugar escogido o destinación ajena [...] La ciudad se volverá desde entonces este envoltorio que une y separa, que juega con aquella tensión. Como un útero incierto, pero remitente" (67). Luego, reafirma su imposibilidad de ingreso: "Sí, reducirá al foráneo que soy. Aunque me incline sobre las secreciones que exhuma su cuerpo, no se me dará a leer. Estoy en la superficie, con los alfabetos. Debo bajar" (68). Resulta imposible conocer la ciudad a pesar de mantener colgado el mapa en la pared y analizarlo diariamente para intentar descifrar su significado:

Agobiado por esta excursión visual que no había logrado acercarlo a la ciudad, Octavio enderezó el mapa contra el respaldo de la silla, sostenido a medias por los dobleces, y se recostó sobre la cama, tendido de espaldas y las manos sobre la nuca... Ahora desde lejos, habiendo suspendido el juego por cansancio, parecía distinguir otras figuras que habían escapado a su primera observación. En Huechuraba, hacia el norte, una avioneta dibujada por un niño parecía a punto de desprenderse del trozo de avenida que la mantenía sujeta a Santiago. Pero estaban los cerros y las montañas que la abrazaban, recortando su forma. Por esta razón los aeropuertos se situaban hacia el oeste, Pudahuel y Cerrillos (31).

La ciudad de Santiago entonces no es un escenario, sino una escritura orgánica que se desplaza en el mapa. El cronotopo y el desplazamiento constante de los cuerpos por las calles de Santiago trazan los caminos para intentar dar un sentido a los personajes, pero una vez realizado el encuentro, ellos no hallan una solución y la ciudad sigue siendo caótica e ilegible. Por eso Sandra le dice a Octavio desde un principio: aquí "No vas 
a poder aprenderte estos recorridos. No están escritos en ningún papel. Aquí vas a tener que vivir y sufrir cada nombre, ubicarte en el pulso de las cosas. Tienen algo como un zurcido invisible" (42). Por ello Sandra es el mapa, tiene los recorridos y ese "zurcido invisible" en su propia piel. Su cuerpo es una extensión de la ciudad; por lo tanto, también será errática y caótica. La relación física de ellos es un paralelo del recorrido y búsqueda en la ciudad. No es una relación formal, sino encuentros sexuales casuales siempre después de un recorrido fallido. La relación del cuerpo y la ciudad ha sido bastante investigada por Richard Sennett: "He intentado comprender cómo estos problemas relacionados con el cuerpo han encontrado expresión en la arquitectura, en la planificación urbana y en la práctica de la misma" (Sennett 1997, 26). Aunque no es un tópico, sino un análisis desde el cuerpo como unidad estructural y su desarrollo temporal con los prejuicios morales, esta idea nos abre la posibilidad de ver la ciudad como un lugar de quiebre espiritual, de insensibilidad, de crisis de la subjetividad, que es precisamente lo que sucede con nuestros personajes al hacer de la experiencia sexual una experiencia social, y del cuerpo una extensión de la ciudad:

Desea que lo toque permeable, desagregado. [...] que vuelva a estar el esqueleto en aquel emplazamiento que permitía la circulación de las partes, fuerza recogida que favorece los otros flancos, cimiento para el adobe, historia sujeta a la escritura telúrica, historia del polvo, de lo que perdura sin sobrevivir.

-Abrázame por el punto flanco, me implora. Vuelve hacia atrás el reloj arquitectural, quítame forma y peso, cúbreme de jeroglíficos mientras intento agotarme con mi verbo, mientras hablo de ti, te hago monumento (109).

No sé si podemos hablar de fracaso de los personajes debido a que la relación íntima de ellos y el intento de recorrer la completitud de la ciudad no tienen un resultado concreto. Parece que el recorrido tiene como resultado un objeto que nunca se encuentra, provocando, por ello, el exceso de lenguaje como consecuencia de ese vacío: el recorrido se convierte en escritura que ellos intentan leer o leerse. El cuerpo y la ciudad se han fusionado convirtiéndose en una cartografía espacio-corporal, señalizada por los diferentes lugares que han visitado e intimado. Es cierto que la ciudad ha negado la recuperación de la memoria y que es una obligación moral encontrarla, pero en este proceso se ha descubierto una escritura 
líquida, serpenteante, como los ríos y las calles que se recorren para buscar otra forma de memoria que no tenga una verdad oficial, que no tenga un único centro desde donde hablar. La fragmentación de las subjetividades y la dispersión de las calles como significantes explotados es, por lo tanto, la alternativa de escribir y habitar.

\section{LOS ESPACIOS IN-CORPORADOS: FRUTA PODRIDA DE LINA MERUANE}

El cuerpo es un elemento fundamental y primario, cultural, histórico y geográficamente específico, ya que, como hemos afirmado, se vive y se habitan los espacios en función de los cuerpos. Por ello el cuerpo es geopolítico, su ubicación está marcada por su posición dentro de circunstancias históricas y geográficas específicas de acuerdo a una jerarquía espacial de escalas de opresión que se inicia desde el cuerpo hacia el exterior, desde políticas privadas o íntimas hacia políticas globales. Como se ha sostenido previamente, los espacios son móviles y los lugares múltiples y diferenciados. Por lo tanto, una mirada geopolítica del cuerpo implica un movimiento fluido hacia diferentes registros espaciales. Se trata, en fin, de cartografiar los puntos de conexión entre los individuos y el lugar.

En Fruta podrida (2007) de Lina Meruane reconocemos dos espacios completamente opuestos: por un lado, el "Ojo Seco", lugar semi-rural donde se produce fruta para exportación y, por otro, una mega ciudad del primer mundo, lugar de huida de la protagonista. Lo interesante en el tratamiento del espacio en esta novela es que logra unir dos espacios que han sido vistos de forma antagónica por la crítica literaria. Por un lado, el espacio rural, que clásicamente funciona dentro de la tradición "lárica" como el lugar de recogimiento y escape del caos citadino y, por otro, las mega ciudades. Ojo Seco es un lugar rural destinado al cuidado de fruta para la exportación. Está dominado por María, la hermana Mayor, que tiene como misión mantener la fruta en excelente estado para ser exportada. Para ello, utiliza diferentes técnicas de saneamiento y desintoxicación por medio de pesticidas para luchar contra las diferentes infecciones que le puedan afectar. La Mayor posee el dominio completo sobre este espacio, ya que da las órdenes, selecciona, califica, erradica, como parte de una cadena científica jerarquizada de mando, donde "no es ella quien inventó 
las reglas de esta desgracia: primero las dictaron científicos extranjeros en conferencias internacionales [...]" (Meruane 2007, 40). Su misión viene de un mandato superior relacionado con la producción a gran escala para el proyecto de economía globalizada. Es así como lo afirma el propio personaje:

Esa es mi responsabilidad, yo decido cuánto de este pesticida y cuánto del otro en los aviones y en el aire, yo soy quien mueve con las dos manos hasta el último músculo de la espalda, la pesada maquinaria del campo; la que da trabajo soy, y la que provee a los supermercados al otro lado del océano, en todos los continentes. En estas manos recae toda la responsabilidad económica y moral; en esta manos, en cada dedo y cada falange (76).

Estamos, por lo tanto, frente a un espacio localizado y acotado que funciona en relación a una red mayor, que es la producción de fruta para la exportación, en forma subterránea, de producción de fetos, por parte de la Mayor, para la venta en hospitales. El Ojo Seco es entonces, en palabras de Saskia Sassen, una "contrageografía"; es decir, un circuito fronterizo, principalmente femenino:

Estos circuitos son enormemente diversos pero comparten una característica: son rentables y generan beneficios a costa de quienes están en condiciones desventajosas. Incluyen el tráfico ilegal de personas destinadas a la industria del sexo y a varios tipos de trabajo en el mercado formal e informal. Incluyen migraciones transfronterizas, indocumentadas o no, que se han convertido en una fuente importante de divisas para los gobiernos de los países emisores $(2003,41)$.

Se trata de espacios de desplazamientos, pensados para la producción en masa. Funcionan con infraestructuras legales e institucionales, pero por medio del abuso de prácticas laborales donde las mujeres son fundamentales. Sassen habla de "feminización de la supervivencia" (53) para referirse a estos circuitos en donde la economía doméstica no es el trabajo, sino la prostitución, la trata de blancas, el tráficos de niños(as). La globalización adopta, así, un sentido de género que no había sido considerado, a pesar que esta forma de economía global es crítica para las mujeres y no neutral como se ha planteado $(59) .^{3}$

3. "Una importante pregunta metodológica reside en saber cuáles son los lugares estraté- 
Fruta podrida muestra el resultado de una economía globalizada de la fruta y de los cuerpos. Ambos actúan como una metonimia del carácter mercantil exitoso que tanto se enorgullece de las cifras nacionales: fruta cuidadosamente sanitizada para la exportación, el cuerpo de una mujer medicamentado que procrea para la ciencia. De este modo, el trabajo de la Mayor es resguardar el proceso de la fruta en forma exacta y eficiente, tanto de la futa como de los fetos que procreará para donar al hospital, que se convierte en una metonimia del Ojo Seco.

El hospital es un espacio biopolítico de control de la vida, administración de la salud de los pacientes y crecimiento del capitalismo que “[ [... no pudo afirmarse sino al precio de la inserción controlada de los cuerpos en el aparato de producción y mediante un ajuste de los fenómenos de población a los procesos económicos" (Foucault 1991, 170). Sin embargo, esta cadena tiene un eslabón suelto en su propia familia, ya que su hermana Zoila, la Menor, sufre la descomposición de su cuerpo. La hermana mayor, experta en el uso de pesticidas y el mantenimiento de la fruta en el galpón, no puede evitar que la enfermedad penetre en su casa y en el cuerpo de su hermana, quien se convierte en una amenaza al esquema de producción de la exportación de la fruta. La enfermedad es, por lo tanto, una forma de disidencia que también se puede exportar. Por ello, la Menor se exporta a sí misma hacia una gran ciudad en el Norte. Este desplazamiento geográfico y de conciencia le permite una búsqueda de identidad propia, ajena a la producción y reproducción que la rodea. Es importante mencionar que el proceso de escritura también es una forma de recorrido que realiza la hermana menor. Si en Cita capital, el recorrido de la ciudad a través de las calles es una forma de escribir y cartografiar la memoria, en Fruta podrida la Menor lleva consigo un "Cuaderno de Composición” donde anota cada una de las dosis de la comida y medicina que debe ingerir, pero ese mismo cuaderno es intervenido -al igual que ella hace con su cuerpo- para crear un "cuaderno deScomposición" donde anota las medidas que luego descompone en versos para afirmar en ellos que:

gicos en los que los procesos económicos internacionales pueden ser estudiados desde una perspectiva feminista. En el caso de la agricultura orientada a la exportación, este lugar estratégico es el nexo entre las economías de subsistencia y las empresas capitalistas" (Sassen, 59). 
KİPUS 44, julio-diciembre 2018

\author{
esta espera con su $S$ intercalada \\ entre sustantivos esa ese descomponiendo \\ mi cuaderno entre mis dedos manchando \\ la superficie cuadriculada de mi cuerpo \\ (55; cursivas en el original).
}

Así, cuerpo, escritura y texto coinciden en la descomposición de un sistema, ya sea económico o escritural. La tachadura del texto es la tachadura al cuerpo sano, vendible, exportable donde la página del cuaderno es la piel de la Menor que está marcada por la herida que se provoca en el pie con una tijera. En ese instante comienza el proceso de pudrición que se acelera con la llegada a la ciudad del país del Norte. Esta ciudad es una megalópolis que puede ser Nueva York o cualquier otra de las grandes ciudades nombradas en la novela. Zoila llega cargando su maleta con dinero, la pierna herida y las tijeras que trae desde Ojo Seco para provocar un atentado al Gran Hospital. En ese proceso de búsqueda, la Menor reconoce el paisaje cosmopolita cubierto de "árboles deshojados, esos postes de luz parados sobre su única pierna te parecen una infinita procesión de lisiado" (127). La ciudad está enferma, contagiada, y ella es la única que puede evitar ese dolor. Por eso, Zoila decide ingresar al hospital y producir un atentado a los enfermos terminales: "Ante todas esas criaturas envueltas en sábanas tienes la convicción de que hay que impedirlo, hay que detener este proceso, aquí, ahora, y todas las veces que sea necesario. Lo harás una y todas las veces que puedas, atacar la maquinaria, desenchufarla, boicotearla..." (133). La enfermedad se debe cortar de raíz, y el lugar elegido es su propio origen: el Gran Hospital de la principal ciudad del Norte. El resto de la historia es presentada a los lectores por medio de un extenso monólogo interior hacia el final de la novela, escrito con una letra distinta, en el que una mujer que expone sus argumentos en favor de la medicina, junto con su intento de diálogo con una mendiga que se encuentra sentada en un banco de una plaza frente a un hospital. A medida que la narración avanza, entendemos que el tiempo ha pasado, que la mendiga es Zoila y que espera el momento de cometer otro atentado. La mujer, que resulta ser una enfermera, intenta persuadir a la mendiga que acepte ayuda médica. Cuando se acerca y percibe el olor a podredumbre, inicia la revisión del cuerpo. Mientras la mendiga mantiene la mirada perdida, la enfermera ausculta el cuerpo que hiede y afirma: "Me detengo, me percato, me pregunto confundida ¿y el tobillo de la mendiga?, ¿¿dónde habrá ido 
a parar el resto de esta mujer? [...] Ay, dónde termina ese cuerpo, dónde está el punto final de esta mujer. Quizás ella o cualquiera por favor me lo diga, y quizás entonces pueda por fin callarme [...]" (185). El "Cuaderno deScomposición" se convierte en el cuerpo descompuesto y cercenado de la propia Zoila, su autora. Ambos se han unido para mostrar el resultado de un capitalismo que arrasa los cuerpos como mercancías. El cuerpo de Zoila se ha convertido en una fruta podrida.

\section{ESPACIOS COMUNITARIOS: IMPUESTO A LA CARNE DE DIAMELA ELTIT}

Si la globalización ha construido espacios para la producción y distribución de objetos en forma rápida y eficiente, movilizando recursos y cuerpos, también ha construido instalaciones que aseguran la circulación acelerada de los mismos:

los no lugares son tanto instalaciones necesarias para la circulación acelerada de personas y bienes (vías rápidas, empalmes de rutas, aeropuertos) como los medios de transporte mismos o los grandes centros comerciales, o también los campos de tránsito prolongado donde se estacionan los refugiados del planeta (Augé 2000, 41).

Se trata de espacios completamente móviles donde no hay sentido de identidad o comunidad, sino más bien son espacios donde se refuerzan las redes multinacionales y se amplifican las individualizaciones. Aunque son espacios de tránsito, los individuos viven atrapados en ellos, ya que son lugares de acceso cotidiano, e incluso algunos, como los grandes centros comerciales, se han transformado en espacio de vivienda, recreación, trabajo y consumo cotidiano. Es por ello que Impuesto a la carne (2010), de Diamela Eltit, presenta los pasillos de un hospital como un espacio preparado para el buen funcionameinto de los cuerpos. Sus personajes son una madre y una hija de doscientos años, que practicamente viven en el hospital ya que están sometidas a diferentes exámenes e intervenciones médicas. La novela es, por tanto, una reflexión política de un capitalismo aberrante en el que estas mujeres denuncian, por medio de la enfermedad y la hemorragia, el saqueo de sus propios cuerpos. El recinto hospitalario representa una alegoría de la patria o de la nación, en el cual las dos mu- 
jeres bicentenarias se han movilizado en forma marginal, por que "[l]a patria se ríe (con carcajadas ominosas) ante nuestras heridas históricas que no cesan de sangrar y la nación no va a reconocer nunca la magnitud de las infecciones que se deslizan por los metales de las camas" (Eltit 2010, 186). Las relaciones de poder se entretejen en el hospital, donde se intenta diagnosticar, intervenir y curar los cuerpos rebeldes de estas dos mujeres. Por esto es necesario dialogar con el concepto de poder, cuerpo-poder, biopoder y sus efectos en las técnicas de autoridad para entender el espacio de la novela como un territorio de múltiples significaciones, y atravesado por una serie de relaciones que intentan crear identidades. De allí la diseminación de significados que conlleva el hospital en la novela. En primer lugar, sabemos que es un lugar público que funciona como privado, ya que es el "hogar" de las mujeres bicentenarias. La visión normada de este espacio es distorsionada por la presencia de estas mujeres: lo transforman en un espacio impúblico que alberga al individuo en su forma más aislada, personal y solitaria, ya que no está destinado a la reunión o encuentro entre personas; al contrario, anula la posibilidad de reunión. En segundo lugar, el hospital se abre a la nación, porque funciona como una doble articulación que provoca múltiples significaciones para denunciar la intervención del cuerpo social, la memoria de los marginados y el saqueo histórico de los órganos. Por lo tanto, encontramos nuevamente, al igual que las novelas anteriores, el espacio como sinécdoque del cuerpo femenino históricamente intervenido y saqueado. El cuerpo de las bicentenarias es un elemento de re-significación conceptual que se pluraliza en cuerpos sociales marginales, porque estos cuerpos son materialidades donde las formas de poder construyen un cuerpo historizado que contiene las cicatrices y heridas de la historia: "cuántos secretos después de una infinidad de tiempo, un tiempo impresionante que puede leerse desde nuestros órganos (siempre colonizados, nunca independientes)" (121). Sin embargo, y esta es la apuesta escritural y política de Eltit, es que son cuerpos porfiados, porque no responden a los tratamientos que con tanta saña se les ha aplicado. Ellas reconocen sus cuerpos anarquistas, y denuncian por medio de la exposición de su fealdad, deformidad y enfermedad el robo histórico de sus cuerpos. No son personajes pasivos o padecientes, sino más bien seres que tienen agencia al decidir posicionarse en el margen del sistema y hacer de su propio cuerpo una página de la historia. Es por ello que después de una intervención quirúrgica, y para evitar que ellas hablen a la nación en la celebración de 
los doscientos años, los médicos dejan a la madre dentro de la hija donde se produce la espera de la cicatrización como un proceso de preparación de los cuerpos para el cambio: "mi madre y yo estamos invadidas por una cantidad incuestionable de pliegues y de vueltas que auguran la posibilidad de una nueva etapa orgánica" (Eltit 2010, 156). Esta nueva etapa será la fundación de una comuna por medio de la fusión de estos cuerpos anarquistas, desde donde podrán reclamar por su participación de la historia en esta celebración de los doscientos años: Ya fusionadas "en la patria de mi cuerpo o en la nación de mi cuerpo, mi madre por fin estableció su comuna. Se instaló una comuna en mí rodeada de órganos que se levantan para protestar por el estado de su historia" (185). Esta comuna, que se produce en la piel y la página de las mujeres, intenta (desde el cuerpo mismo) elaborar un tipo de testimonio alterno donde la herida, la sangre y la atrofia representan aquello que es imposible testimoniar.

Para finalizar, el espacio en las obras analizadas es el escenario de las luchas de poder que se disputan un territorio para instalar las tecnologías que facilitarán la normalización de los individuos; por esto, los personajes se resisten a esas técnicas fracturando esas mismas construcciones mediante el movimiento constante de sus cuerpos y la manera en que ocupan esos lugares: hacen de la marginalidad una de sus formas de definición. Por ello, el sujeto deviene subjetividad violentada por el modo de hacerse en ese espacio movible siempre al borde de una marginalidad diferente. Los personajes entonces pueden ser marginales porque habitan el margen geográfico o económico, como sucede en Fruta podrida, o personajes anormales que no habitan necesariamente el margen, pero su condición subjetiva los hace bordear la periferia, como es el caso de Cita capital, o los personajes desagregados que pueden vivir en el margen, pero se agregan a los centros desde prácticas diferentes a las oficiales como sucede con las bicentenarias en Impuesto a la carne. En cualquiera de los casos, son siempre personajes que no se identifican con las prácticas que la oficialidad política, económica y cultural les ofrecen. El espacio privado es tachado para hacerse público y exhibir los cuerpos de los personajes que realizan un espectáculo del cual disfrutan, no son presentados desde una perspectiva sociológica con situaciones dramáticas (aún cuando estas sean válidas). Este es el punto más importante en mi reflexión: aunque estos personajes sean marginales o precarios, levantan su voz con su sola presencia en las obras. * 
KİPUS 44, julio-diciembre 2018

\section{Bibliografia}

Augé, Marc. 2000. Los no lugares. Espacios del anonimato. Una antropología de la sobremodernidad. Barcelona: Gedisa.

Cisternas, Cristián. 2009. Imagen de la ciudad en la literatura hispanoamericana y chilena contemporánea. Santiago de Chile: Editorial Universitaria.

De Certeau, Michel. 1986. La Invención de lo cotidinano I. Artes de hacer. México, D. F.: Universidad Iberoamericana.

Duchesne, Juan. 2001. Ciudadano insano. Ensayos bestiales sobre cultura y literatura. San Juan: Ediciones Callejón.

Eltit, Diamela. 2010. Impuesto a la carne. Santiago de Chile: Seix Barral.

Foucault, Michel. 1991. Historia de la sexualidad: la voluntad de saber. Vol. I, Madrid: Siglo Veintiuno.

Grosz, Elizabeth. 1995. Space, Time, and Perversion: Essays on the Politics of Bodies. New York: Routledge.

Guerra, Lucía. 2014. Ciudad, género e imaginarios urbanos en la narrativa latinoamericana. Santiago de Chile: Cuarto Propio.

Lefebvre, Henri. 2013 [1974] La producción del espacio. Madrid: Capitán Swing.

Llarena, Alicia. 2007. Espacio, identidad y literatura en hispanoamérica. Sinaloa: Universidad Autónoma de Sinaloa.

Massey, Doreen. 2005. "La Filosofía y la política de la espacialidad: algunas consideraciones". En Pensar este tiempo. Espacios, afectos, pertenencias, Leonor Arfuch, editora. Buenos Aires: Paidós. 103-27.

Meruane, Lina. 2007. Fruta podrida. Santiago, Chile: Fondo de Cultura Económica Chile.

Santa Cruz, Guadalupe. 1992. Cita capital. Santiago de Chile: Cuarto Propio.

Sassen, Saskia. 2003. Contrageografías de la globalización. Género y ciudadania en los circuitos transfronterizos. Madrid: Traficante de sueños.

Sennett, Richard. 1997. Carne y piedra. El cuerpo y la ciudad en la civilización occidental. Madrid: Alianza editorial. 